\title{
microRNA-944 overexpression is a biomarker for poor prognosis of advanced cervical cancer
}

\author{
Sunyoung Park ${ }^{1 \dagger}$, Jungho Kim" ${ }^{\dagger}$, Kiyoon Eom, Sehee Oh', Sunghyun Kim², Geehyuk Kim', Sungwoo Ahn',
} Kwang Hwa Park ${ }^{3}$, Dawn Chung ${ }^{4^{*}}$ and Hyeyoung Lee ${ }^{1 *}$

\begin{abstract}
Background: One-third of cervical cancer patients are still diagnosed at advanced stages. The five-year survival rate is decreased in about 50\% of advanced stage cervical cancer patients worldwide, and the clinical outcomes are remarkably varied and difficult to predict. One of the miRNAs known to be associated with cancer tumorigenesis is miR-944. However, the prognostic value of miR-944 in cervical cancer has not been fully investigated. The aim of this study was to analyze clinical significance and prognostic value of miR-944 in cervical cancer.
\end{abstract}

Methods: The expression levels of miR-944 were detected using quantitative reverse transcription polymerase chain reaction in five types of cervical cancer cell lines and 116 formalin-fixed paraffin-embedded (FFPE) cervical tissues. The association between the expression levels of miR-944 and prognostic value was analyzed using the Kaplan-Meier analysis and Cox proportional hazards model.

Results: The expression levels of miR-944 in cervical cancer tissues were significantly higher compared with those in normal tissues $(P<0.0001)$. Moreover, the expression levels of miR-944 in cervical cancer cell lines and FFPE tissues with human papillomavirus (HPV) infection were significantly higher compared to those without HPV infection $(P<0.01$ and $P=0.02)$. High miR-944 expression was also markedly associated with bulky tumor size $(P=0.026)$, advanced International Federation of Gynecology and Obstetrics $(F \mid G O)$ stage $(P=0.042)$, and lymph node metastasis $(P=0.030)$. In particular, high miR-944 expression group showed shorter overall survival than the low miR-944 expression group in the advanced $\mathrm{FIGO}$ stage $(84.4 \%$ vs. $44.4 \%, \mathrm{HR}=4.0$, and $P=0.01)$.

Conclusions: These results suggest that miR-944 may be used as a novel biomarker for improving prognosis and as a potential therapeutic target.

Keywords: microRNAs, Survival, Prognosis, Uterine cervical neoplasm

\section{Background}

Cervical cancer is the fourth most common cancer in women worldwide after cancer of the breast, colon, and lung [1]. According to the World Health Organization (WHO), each year approximately 528,000 new cases are

\footnotetext{
* Correspondence: dawny1004@yuhs.ac; hyelee@yonsei.ac.kr

'Sunyoung Park and Jungho Kim contributed equally to this work.

${ }^{4}$ Department of Obstetrics and Gynecology, Gangnam Severance Hospital, Yonsei University College of Medicine, 146-92 Dongok-dong, Gangnam-gu, Seoul, Republic of Korea

'Department of Biomedical Laboratory Science, College of Health Sciences, Yonsei University, 1 Yonseidae-gil, Wonju-si, Gangwon-do 26493, Republic of Korea

Full list of author information is available at the end of the article
}

recorded, and 266,000 deaths occur due to cervical cancer [2]. Cervical cancer is mainly caused by infection with high-risk human papillomavirus (HR-HPV) genotypes [3]. With the development of screening and prevention methods of cervical cancer such as HPV co-testing and HPV vaccination, early diagnosis programs of cervical dysplasia and cancer lead to decrease the incidence, morbidity, and mortality of cervical cancer [4].

However, nearly $50 \%$ out of all cervical cancer patients worldwide are still diagnosed with stages IB2 to IVA according to International Federation of Gynecology and Obstetrics (FIGO), whereas about one-third of patients diagnosed with cervical cancer in Korea presented locally

(c) The Author(s). 2019 Open Access This article is distributed under the terms of the Creative Commons Attribution 4.0 International License (http://creativecommons.org/licenses/by/4.0/), which permits unrestricted use, distribution, and reproduction in any medium, provided you give appropriate credit to the original author(s) and the source, provide a link to the Creative Commons license, and indicate if changes were made. The Creative Commons Public Domain Dedication waiver (http://creativecommons.org/publicdomain/zero/1.0/) applies to the data made available in this article, unless otherwise stated. 
advanced stage of the disease [5]. Currently, the standard treatment guideline for patients with advanced FIGO stage IIB and more than stage IIB is radiotherapy combined with platinum-based chemotherapy [6]. Unfortunately, these patients have a higher recurrence rate and a worse survival rate in the first 5 years [5]. Therefore, it is of great importance to identify a novel biomarker that can reliably detect cervical cancer and improve clinical monitoring.

microRNAs (miRs or miRNAs), small non-coding RNAs consisting of approximately 22 nucleotides, regulate gene expression by binding to partially or fully complementary sequences in target mRNAs, resulting in translational inhibition or mRNA degradation, respectively [5]. miRNAs have been suggested to function as oncogenes or tumor suppressors based on their function of inhibiting the expression of tumor suppressive or oncogenic target mRNAs, respectively [6-8]. Numerous studies have shown that dysregulation of miRNAs plays an essential role in cell proliferation, cell cycle regulation, differentiation, and apoptosis and is related to various tumors such as colon, gastric, breast, lung, and cervical cancers [9-13].

miR-944 is located in the intron of the tumor protein p63 gene (TP63) mapped to chromosome 3q28. Previous reports show that miR-944 functions as an oncogene in a number human cancers, including cervical cancer, endometrial cancer, breast cancer, and lung cancer by promoting cell migration, proliferation, and invasion [14-17]. However, some studies have reported that miR-944 can function as a tumor suppressor, inhibiting migration in colorectal cancer, gastric cancer and breast cancer [18-20]. In cervical cancer, miR-944 promotes cell proliferation and migration in CaSki and HeLa cervical cancer cell lines $[16,21]$. To our knowledge, there are no other further studies on the clinical relevance of miR-944 in cervical cancer, and specifically in terms of prognostic value.

Human papillomavirus infection is known to one of the most significant risk factors for cervical cancer [22]. Several studies suggested that the sustained expression of the two oncogenic genes E6 and E7 of HPV is involved in cervical cancer progression by degradation of $\mathrm{p} 53$ and deactivation of retinoblastoma protein (pRB) [23-27]. Recently, miRNA sequencing data from The Cancer Genome Atlas (TCGA) was reported that miRNA clusters such as miR-205-5p, miR-944, miR-200a-5p, miR-30a-5p, miR-338-3p, miR-224$5 \mathrm{p}$, and miR-193b-3p were associated with cervical cancer and especially miR-944 was shown the significant difference between HPV positive and HPV negative cervical cancer [28]. However, there is no further study of the relationship between miR-944 and HPV E6/E7 expression in cervical cancer.

In this study, the prognostic value of miR-944 was investigated using 116 formalin-fixed paraffin-embedded
(FFPE) cervical cancer tissues and normal tissues. Furthermore, the association between miR-944 and HPV E6/E7 mRNA-positive or -negative was explored.

\section{Methods \\ Study population}

A total of 66 FFPE cervical cancer tissues and 50 FFPE normal cervical tissues were collected between January 2010 and December 2014. A total of 66 cervical cancer cases data on age, tumor size, FIGO stage, lymph node metastasis, and HPV infection were retrospectively reviewed from patient electrical medical records. The 50 FFPE normal cervical tissues consisted of 44 patients with non-cervical, benign, uterine disease and six cervical cancer patients with tumor-matched non-cancerous tissues (Table 1). This study was approved by the Institutional Ethics Committee of Yonsei University Wonju Severance Christian Hospital (approval no. CR315052), and all subjects provided written informed consent.

\section{Cell culture}

Cervical cancer cell lines C33A (HPV-negative), SiHa (HPV 16), Caski (HPV 16), HeLa (HPV 18), and ME180 (HPV 18, 68) were purchased from the Korean Cell Line

Table 1 Clinical characteristics

\begin{tabular}{|c|c|c|}
\hline Features & Cervical cancer, N (\%) & Normal, N (\%) \\
\hline Total, n (\%) & $66(100.0)$ & $50(100.0)$ \\
\hline \multicolumn{3}{|l|}{ Age } \\
\hline$<45$ years & $20(30.3)$ & $20(40.0)$ \\
\hline$\geq 45$ years & $46(69.7)$ & $30(60.0)$ \\
\hline \multicolumn{3}{|c|}{ Histological type } \\
\hline ADC & 7 (10.6) & \\
\hline SCC & $59(89.4)$ & \\
\hline \multicolumn{3}{|l|}{ Tumor size } \\
\hline$<4 \mathrm{~cm}$ & $30(45.5)$ & \\
\hline$\geq 4 \mathrm{~cm}$ & $36(54.5)$ & \\
\hline \multicolumn{3}{|l|}{ FIGO stage } \\
\hline $\mid A-\| A$ & $29(43.9)$ & \\
\hline IIB-IVB & $37(56.1)$ & \\
\hline \multicolumn{3}{|c|}{ Lymph node metastasis } \\
\hline No & $35(53.0)$ & \\
\hline Yes & $31(47.0)$ & \\
\hline \multicolumn{3}{|c|}{ HPV E6/E7 expression } \\
\hline Negative & $12(18.2)$ & \\
\hline Positive & $54(81.8)$ & \\
\hline \multicolumn{3}{|l|}{ Survival } \\
\hline Alive & $52(78.8)$ & \\
\hline Died & $14(21.2)$ & \\
\hline
\end{tabular}

Abbreviations: FIGO International Federation of Gynecology 
Bank (Seoul, Republic of Korea) and the American Type Culture Collection (Manassas, VA, USA). Dulbecco's modified Eagle's medium (DMEM) with $10 \%$ fetal bovine serum (FBS; Gibco, Carlsbad, CA, USA) and 1\% penicillin/streptomycin (Gibco, Carlsbad, CA, USA) was used to maintain the cells in tissue culture and the five cell lines were maintained at $37^{\circ} \mathrm{C}$ with $5 \% \mathrm{CO}_{2}$.

Deparaffinization of FFPE tissue and total RNA extraction For total RNA extraction from FFPE cervical tissue, three to four $10-\mu \mathrm{m}$-thick sections were transferred to $1.5 \mathrm{~mL}$ tube each. Before extracting RNA, the paraffin was removed from the tissue sections by adding $160 \mu \mathrm{L}$ of deparaffinization solution (Qiagen, Hilden, Germany) followed by incubation for $3 \mathrm{~min}$ at $56^{\circ} \mathrm{C}$. Total RNA extraction was extracted according to the manufacturer's protocol (Qiagen RNeasy FFPE kit, Qiagen). Next, the concentration of the total RNA was measured with an Infinite 200 spectrophotometer (Tecan, Salzburg, Austria). Total RNA was stored at $-80^{\circ} \mathrm{C}$ until used.

\section{microRNA RT-qPCR analysis}

We used the TaqMan miRNA Reverse Transcription kit (Applied Biosystems, Foster City, CA, USA) to synthesize cDNA according to the manufacturer's instructions. Reverse transcription reactions were performed using $10 \mathrm{ng}$ of total RNA and specific reverse transcription primers (Life Technologies) for Homo sapiens (hsa)-miR-944 (assay ID 002189), and the internal reference RNU6B (assay ID 001093). Reverse transcription was performed at $16^{\circ} \mathrm{C}$ for $30 \mathrm{~min}, 42^{\circ} \mathrm{C}$ for $30 \mathrm{~min}, 85^{\circ} \mathrm{C}$ for $5 \mathrm{~min}$.

After the reverse transcription, quantitative $\mathrm{PCR}$ reaction was performed using the TaqMan microRNA assay (Applied Biosystems) according to the manufacturer's instructions. Briefly, the initiation step of PCR cycling conditions at $95^{\circ} \mathrm{C}$ for $10 \mathrm{~min}$, followed by an amplification step of 40 cycles at $95^{\circ} \mathrm{C}$ for $15 \mathrm{~s}$ and $60^{\circ} \mathrm{C}$ for $60 \mathrm{~s}$. The miR-944 expression levels were calculated via the comparative cycle threshold $\left(\mathrm{C}_{\mathrm{T}}\right)$ method. The $\mathrm{C}_{\mathrm{T}}$ values of miR-944 were normalized to the level of RNU6B.

\section{HPV E6/E7 mRNA RT-qPCR assay}

M-MLV reverse transcriptase kit (Invitrogen, Carlsbad, CA, USA) was used for complementary DNA (cDNA) synthesis. Briefly, add $0.25 \mu \mathrm{g}$ random hexamers, $1 \mu \mathrm{L}$ $10 \mathrm{mM}$ dNTP mix, and $5 \mu \mathrm{L}$ DEPC-treated water and $10 \mu \mathrm{L}$ total RNA. The mixture was then incubated at $65^{\circ} \mathrm{C}$ for $5 \mathrm{~min}$ and quickly cooled on ice. After that, $4 \mu \mathrm{L}$ of $5 \mathrm{x}$ Buffer, $2 \mu \mathrm{L}$ of $0.1 \mathrm{M}$ dithiothreitol (DTT) and $1 \mu \mathrm{L}$ of M-MLV Reverse Transcriptase (RT) were added to the first mix. The reverse transcriptase reaction was carried out at $25^{\circ} \mathrm{C}$ for $10 \mathrm{~min}$, at $37^{\circ} \mathrm{C}$ for $50 \mathrm{~min}$, and at $70{ }^{\circ} \mathrm{C}$ for $15 \mathrm{~min}$.
Detection of HPV E6/E7 mRNA in FFPE cervical tissues was performed by OPTIMYGENE HPV E6/E7 mRNA RT-qDx assay kit (Optipharm M\&D, Osong, Republic of Korea), according to the manufacturer's instructions. The reverse transcription quantitative PCR (RT-qPCR) assay was carried out using the CFX96 system (Bio-Rad, Hercules, CA). Real-time PCR amplification for HPV E6/ E7 mRNA was performed in a total volume of $20 \mu \mathrm{L}$, containing $10 \mu \mathrm{L}$ of $2 \mathrm{x}$ Thunderbird probe qPCR mix (Toyobo, Osaka, Japan), $5 \mu \mathrm{L}$ primer and TaqMan probe mixture, $3 \mu \mathrm{L}$ distilled water and $2 \mu \mathrm{L}$ template cDNA. Positive and negative controls were contained per each procedure. Reaction conditions of real-time PCR were as follows: $95^{\circ} \mathrm{C}$ for $3 \mathrm{~min}$, and 40 cycles of $95^{\circ} \mathrm{C}$ for $3 \mathrm{~s}$ and $55^{\circ} \mathrm{C}$ for $30 \mathrm{~s}$. Glyceraldehyde-3-phosphate dehydrogenase (GAPDH) was used as an endogenous control and confirmation of mRNA degradation.

\section{The Cancer genome atlas (TCGA) analysis}

Raw data for miR-944 and clinical information in cervical cancer were extracted from the TCGA open source repository website (http://firebrowse.org/) on 01/28/2016. Variables, such as follow-up times, tumor stage, race, and reads per million of miR-944 in 180 cervical cancer patients were included. Information of HPV E6/E7-positive and HPV E6/E7-negative cervical cancers matched with patients from TCGA open source repository website was obtained from the Banister et al. study [29]. The HPV E6/ E7 expression were classified as HPV alpha-9, HPV alpha-7, and HPV negative cervical cancer based on HPV E6/E7 expression. The reads per million of miR-944 according to HPV E6/E7 expression were analyzed by student t-test.

\section{Statistical analysis}

All statistical analyses were performed using GraphPad Prism version 6 software (La Jolla, CA, USA) and SPSS version 21.0 software (IBM, Armonk, NY, USA). Wilcoxon matched-pairs singed rank test was performed for comparison between the paired cervical normal and cancer tissues. Student's t-test were conducted for comparison between normal and cancer tissues. To identify whether miR-944 is affected by HPV E6/E7 mRNA positive or negative cervical cancer tissues, the expression levels of miR-944 was compared by student's t-test. To determine the clinical cut-off value of miR-944 between cervical cancer and normal tissues, receiver operator characteristic (ROC) curve analysis were performed. Based on the clinical cut-off value, cases were divided into two groups according to the expression level of miR-944 (high miR-944 vs. low miR-944). Potential associations between the expression of miR-944 and various prognostic parameters were analyzed by the Chi-square test. Survival was estimated by the Kaplan-Meier method and evaluated by 
the log-rank test. Multivariate analyses of prognostic values were evaluated using the Cox proportional hazards model. In all analyses, a $P$-value of less than 0.05 was considered statistically significant.

\section{Results}

miR-944 expression levels in normal and cancerous cervical tissues

To explore the expression levels of miR-944 in cervical cancer cells, six cervical cancer patients with tumor-matched non-cancerous tissues were evaluated by RT-qPCR. The results showed that the expression levels of miR-944 were significantly higher in cervical cancer tissues than those in matched non-cancerous cervical tissues $(n=6, P=0.031$; Fig. 1a). Subsequently, similar expression levels of miR-944 were observed by RT-qPCR in 66 cervical cancer tissues and 50 normal cervical tissues. The expression levels of miR-944 in the cervical cancer tissues were significantly higher than in normal cervical tissues $(P<0.0001$; Fig. $1 \mathrm{~b})$. The expression level of miR-944 in cervical cancer and normal tissues was plotted as a ROC curve to assess cut-off values for discriminating cervical cancer from normal tissues. At the optimal cut-off point, the area under the curve (AUC) of miR-944 was $0.79(P<0.0001 ; 95 \%$ confidence interval (CI), 0.71-0.86 (Fig. 1c).

\section{Association between miR-944 expression and HPV infection status}

Since the main cause of cervical cancer is HPV infection, we investigated whether the expression of miR-944 and HPV infection status were related. The expression levels of miR-944 in cervical cancer cell lines with or without HPV infection were compared. Expression levels of miR-944 in the HPV-positive cervical cancer cell lines SiHa (HPV 16-infection), Caski (HPV 16 infection),
HeLa (HPV 18 infection) and ME180 (HPV 18, 68 infection) were significantly higher than in the HPV-negative cervical cancer line C33A $(P<0.01, P<0.01, P<0.01$, and $P<0.001$, respectively), supporting the hypothesis that HPV infection may affect miR-944 expression levels (Additional file 1).

Next, the expression levels of miR-944 in the 66 FFPE cervical cancer tissues according to HPV infection status were investigated. Among 54 HPV E6/E7 mRNA expression-positive and $12 \mathrm{HPV}$ E6/E7 mRNA expression-negative cancer tissues, the expression levels of miR-944 were significantly up-regulated in HPV E6/E7 mRNA expression-positive cancer tissues $(P=0.02$; Fig. 2). Furthermore, 171 cervical cancer tissues comprised of samples from various races and HPV types (TCGA data) classified by HPV-E6/E7 based genes were additionally analyzed (Additional file 2). Similarly, the expression levels of miR-944 in TCGA data were also significantly up-regulated in HPV-E6/E7 positive cancer tissues, especially alpha 9 and alpha 7 species $(P<0.0001$; Additional file 3).

\section{Associations between miR-944 expression and clinicopathological characteristics}

To investigate the association between the miR-944 expression levels and clinicopathological characteristics, Chi-square test was used to analyze data from 66 cervical cancer patients. miR-944 expression levels showed no association with age and histological type $(P=0.815$ and $P=0.174)$. However, miR-944 expression levels showed significant association with tumor size, FIGO stage, and lymph node metastasis, indicating their usefulness as prognostic parameters $(P=0.026, P=0.042$, and $P=0.030$; Table 2). The expression of miR-944 was low in tumors less than $4 \mathrm{~cm}(76.7 \%)$, in the early FIGO
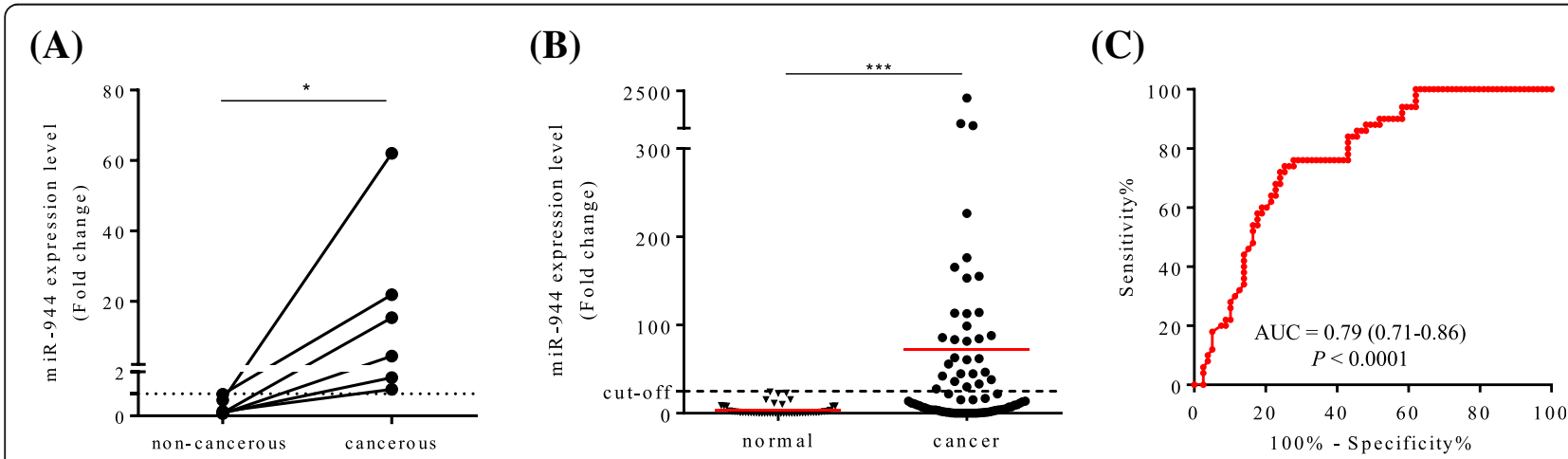

Fig. 1 Relative miR-944 expression in FFPE cervical cancer tissues and normal cervical tissues. a Relative miR-944 expression in paired samples ( $n$ =6). The mean miR-944 expression level in the cervical cancer tissues was significantly higher than the pair-matched non-cancerous cervical tissues $(P=0.031)$. b The relative miR-944 expression levels were compared between cervical cancer $(n=66)$ and normal cervical tissues $(n=50)$. The miR-944 expression levels in cervical cancer tissues were significantly higher than those in normal cervical tissues $(P<0.0001)$. c Receiver operator characteristic curve analysis for determining cut-off value is distinguishing normal and cancer cells was performed. Optimal cut-off point for miR-944 with an AUC of 0.79 ( $P<0.0001 ; 95 \%$ confidence interval $[C l], 0.71-0.86)$. ${ }^{*} P<0.05$, ${ }^{*} P<0.01$, and ${ }^{* * *} P<0.001$ 


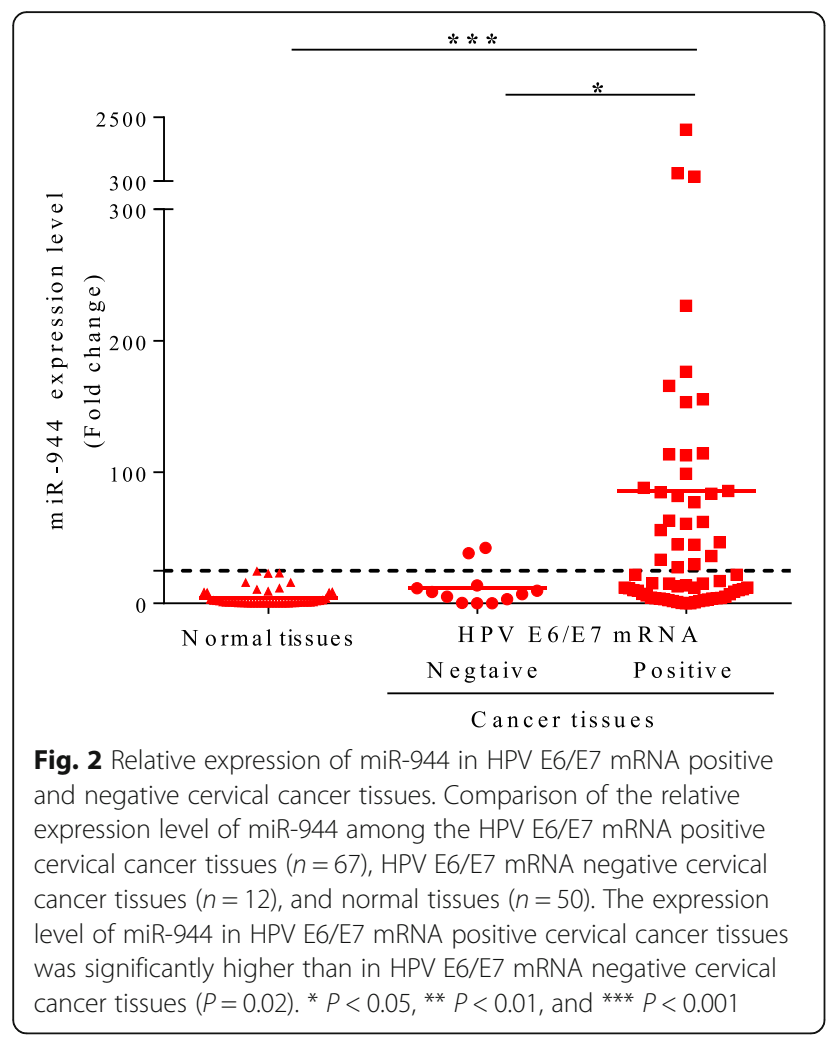

Table 2 Association between the miR-944 expression levels and clinicopathological characteristics of patients with cervical cancer

\begin{tabular}{lllll}
\hline Features & No. (\%) & \multicolumn{2}{l}{ miR-944 expression } & $P$ \\
\cline { 5 - 6 } & $(n=66)$ & Low, $\mathrm{n}(\%)$ & High, $\mathrm{n}(\%)$ & \\
\hline No. of patients & 66 & $41(62.1)$ & $25(37.9)$ & \\
Age & & & & 0.815 \\
$\quad<45$ years & 20 & $12(60.0)$ & $8(40.0)$ & \\
$\quad \geq 45$ years & 46 & $29(63.0)$ & $17(37.0)$ & \\
Histological type & & & & 0.174 \\
ADC & 7 & $6(85.7)$ & $1(12.9)$ & \\
$\quad$ SCC & 59 & $35(59.3)$ & $24(40.7)$ & \\
Tumor size & & & & 0.026 \\
$\quad<4$ cm & 30 & $23(76.7)$ & $7(23.3)$ & \\
$\quad \geq 4$ cm & 36 & $18(50.0)$ & $18(50.0)$ & \\
FIGO stage & & & & 0.042 \\
IA-IIA & 29 & $22(75.9)$ & $7(24.1)$ & \\
IIB-IVB & 37 & $19(51.4)$ & $18(48.6)$ & \\
Lymph node metastasis & & & & 0.030 \\
No & 35 & $26(74.3)$ & $9(25.7)$ & \\
Yes & 31 & $15(48.4)$ & $16(51.6)$ & \\
\hline
\end{tabular}

Abbreviation; FIGO International Federation of Gynecology; $P$, Chi-square $p$-value stage $(75.9 \%)$, and in the absence of lymph node metastasis (74.3\%). Interestingly, patients with tumors larger than $4 \mathrm{~cm}$, advanced FIGO stage, and lymph node metastasis showed low and high of miR-944 levels at similar percentages (50 and $50 \%$ for larger than $4 \mathrm{~cm}$ tumors, 51.4 and 48.6\% for advanced FIGO stage, and 48.4 and $51.6 \%$ for lymph node metastasis). Not only the conventional prognostic parameters but also biological characteristics of miR-944 provide another additional information. Therefore, we further analyzed whether miR-944 is useful as a prognostic marker that can provide additional information to existing prognostic factors.

\section{Association between miR-944 expression and patient survival}

To explore overall survival in patients with high and low expression of miR-944, overall survival time was obtained from the date of the initial surgery to time of death. Kaplan-Meier survival analysis showed poor prognosis with high miR-944 expression (Log-rank test, $P=0.003$ ). A 5-year survival rate of $90.2 \%$ in patients with low miR-944 expression levels $(n=41)$ ranged from 49.9 to 59.6 months (mean, 54.8 months), whereas 5 -year survival rate of $60.0 \%$ in patients with high miR-944 expression levels $(n=25)$ ranged from 29.8 to 49.8 months (mean, 39.8 months) (Fig. 3a).

To compare the prognostic parameters and miR-944, which is a newly found prognostic marker, Cox proportional hazards regression was used to investigating the association between survival time of patients and clinical parameters together with miR-944 expression. Using univariate analysis, high miR-944 expression levels and three clinicopathological parameters which were tumor size $(\mathrm{HR}=5.6,95 \% \mathrm{CI} 1.3-25.2, P=0.024)$, FIGO stage (HR $=11.8,95 \%$ CI 1.5-90.2, $P=0.018)$, and lymph node metastasis $(\mathrm{HR}=8.2,95 \% \mathrm{CI} 1.8-36.5, P=0.006)$ were associated with poor prognosis of cervical cancer. All significant parameters were further analyzed using multivariate analysis. The results revealed that FIGO stage $(\mathrm{HR}=9.1,95 \% \mathrm{CI} 1.2-71.1, P=0.034)$ and high miR-944 expression $(\mathrm{HR}=3.5,95 \%$ CI 1.1-11.2, $P=$ 0.034 ) could be independent prognostic factors for the patients with cervical cancer (Table 3).

In an advanced FIGO stage $(n=37)$, Kaplan-Meier survival analysis revealed the poor prognosis of patients with high miR-944 expression levels (Log-rank test, $P=$ 0.01 ). The 5-year survival rate in patients with low miR-944 expression levels $(n=19)$ was $84.2 \%$ and ranged from 42.7 to 60.3 months (mean, 51.5 months), whereas the 5 -year survival rate in patients with high miR-944 expression levels $(n=18)$ was $44.4 \%$ and ranged from 19.9 to 44.1 months (mean, 32.0 months) (Fig. 3b). 

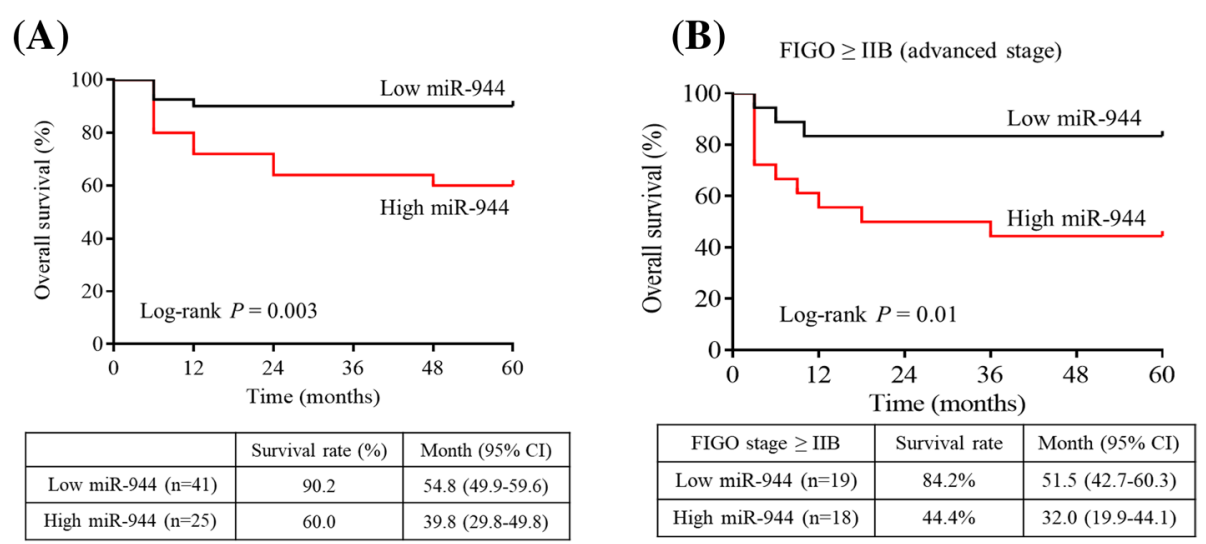

Fig. 3 Kaplan-Meier survival curve for patients with cervical cancer according to miR-944 expression. a High or low miR-944 expression level were determined using the cut-off value of miR-944 in cervical cancer and normal tissues. High miR-944 expression level group showed poor survival rates compared to low miR-944 expression level group (log-rank test, $P=0.003$ ). b Among the 37 patients with an advanced FIGO stage,

including of 19 patients with low miR-944 expression and 18 with high miR-944 expression, the overall survival rate was 84.2 and $44.4 \%$ (log-rank test, $P=0.01)$

\section{Discussion}

In this study, we investigated miR-944 expression levels in FFPE cervical cancer and normal tissues by RT-qPCR methods, and the result showed poor prognosis in patients with high miR-944 expression levels and in an advanced stage of cervical cancer. In addition, we demonstrated that there was an association between high expression levels of miR-944 and expression levels of HPV oncogene E6/E7 in HPV-positive cervical cancer cells by analysis of FFPE cervical cancer tissues and TCGA data.

The expression levels of miR-944 were significantly higher in cervical cancer tissues as compared to those in paired non-cancerous tissues $(n=6)$ (Fig. 1), which

Table 3 Univariate and multivariate analysis of prognostic factors together with miR-944 expression in cervical cancer

\begin{tabular}{|c|c|c|c|c|c|c|}
\hline \multirow[t]{3}{*}{ Features } & \multicolumn{6}{|c|}{ Overall survival } \\
\hline & \multicolumn{3}{|c|}{ Univariate analysis } & \multicolumn{3}{|c|}{ Multivariate analysis } \\
\hline & $\mathrm{HR}$ & $95 \% \mathrm{Cl}$ & $P$ & $\mathrm{HR}$ & $95 \% \mathrm{Cl}$ & $P$ \\
\hline \multicolumn{7}{|l|}{ Ages } \\
\hline$<45$ years vs. $\geq 45$ years & 2.8 & $0.6-12.4$ & 0.18 & & & \\
\hline \multicolumn{7}{|l|}{ Histological type } \\
\hline ADC vs. SCC & 1.5 & $0.2-11.8$ & 0.68 & & & \\
\hline \multicolumn{7}{|l|}{ Tumor size } \\
\hline$<4 \mathrm{~cm}$ vs. $\geq 4 \mathrm{~cm}$ & 5.6 & $1.3-25.2$ & 0.024 & & & \\
\hline \multicolumn{7}{|l|}{ FIGO stage } \\
\hline$<l l b$ vs. $\geq \| b$ & 11.8 & $1.5-90.2$ & 0.018 & 9.1 & $1.2-71.1$ & 0.034 \\
\hline \multicolumn{7}{|l|}{ Lymph node metastasis } \\
\hline no vs. yes & 8.2 & $1.8-36.5$ & 0.006 & & & \\
\hline miR-944 expression & & & & & & \\
\hline
\end{tabular}

Negative vs. Positive $\quad \begin{array}{lllllll}4.7 & 1.5-15.0 & 0.009 & 3.5 & 1.1-11.2 & 0.034\end{array}$

Abbreviations: ADC Adenocarcinoma, SCC Squamous cell carcinoma, FIGO International Federation of Gynecology suggested that miR-944 plays a role in tumorigenesis through clinical cervical cancer tissues. Xie et al. (2015) also had shown that high miR-944 expression levels are associated with tumorigenesis of cervical cancer, based on analysis of cervical cancer cell lines (Caski and HeLa) [16]. We further examined 66 cervical cancer and 50 normal FFPE samples and showed that the expression of miR-944 in cervical cancer was up-regulated which was in line with previous reports [16].

To gain insight into the clinical significance and prognostic value of miR-944, we investigated the relationship between miR-944 expression levels and the clinicopathological characteristics of cervical cancer patients and found that expression of miR-944 was firmly related to the tumor size, FIGO stage, and lymph node metastasis (Table 2). Ma et al. reported that up-regulation of miR-944 has also been associated with lymph node metastasis and advanced stage of lung squamous cell carcinoma [30].

Furthermore, survival analysis of cervical cancer patients showed that high expression levels of miR-944 were associated with poor survival prognosis (Fig. 3a). As a prognostic marker, FIGO stage and high miR-944 expression levels were shown useful prognostic indicators of poor survival (Table 3). Notably, in advanced cervical cancer, high miR-944 expression levels were significantly poorer prognosis than low miR-944 expression levels (Fig. 3b).

Previous studies have attempted to identify the mRNA target of miR-944 in cervical cancer, and Xie et al. showed that miR-944 has two target genes, HECT domain ligase W2 (HECW2), which are known to regulate p63 stabilization, and S100P binding protein (S100PBP), which is known to reduce adhesion and invasion. miR-944 was predicted to play an oncogenic role in 
cervical cancer malignancy by repressing these two genes (HECW2 and S100PBP) that function as a tumor suppressors [16].

Several studies have reported that the expression levels of some miRNAs are associated with poor prognosis in cervical cancer, such as downregulation of miR-335 from Wang et al. [31], down-regulation of miR-145 and upregulation of miR-9 from Azizmohammadi et al. [32]. Recently, Jiang et al. suggested that down-regulation of circulating miR-101 is associated with poor prognosis of cervical cancer [33]. Our study also suggests that high expression of miR-944 could be of clinical relevance for poor prognosis. The miR-944 expression has been analyzed in colorectal, bladder, and breast cancer. High miR-944 expression levels have been associated with tumor recurrence in colorectal cancer [34] and chemo-resistance in bladder cancer [35]. He et al. found that miR-944 is significantly up-regulated in the blood and tumor tissues of breast cancer patients [36]. Like our study, miR-944 is remarkable tumor-associated microRNA.

Interestingly, in our study, miR-944 expression in HPV E6/E7 mRNA-positive cervical cancer was higher than that in HPV E6/E7 mRNA-negative cervical cancer $(P=$ 0.02; Fig. 2). Meanwhile, among five cervical cancer cell lines, the expression of miR-944 in cervical cancer cell lines with HPV infection ( $\mathrm{SiHa}$ and HeLa, Caski, and ME180) was significantly higher than that in the cervical cancer cell line without HPV infection (C33A) (Additional file 1) as well as TCGA data (Additional file 3), analyzed by using individual miR-944 reads and HPV E6/E7 expression status. It suggests that up-regulation of miR-944 is associated with HPV infection and the carcinogenic processes of the E6 and $E 7$ genes. Recently, microRNA heat map categorized by HPV infection and cervical cancer subtypes from TCGA projects also showed that the levels of miR-944, miR-767-5p, and miR-105-5p between HPV-positive and negative cancer were distinctively expressed [28]. Taken together, our results supported that miR-944 expression levels are closely related to HPV infection.

HPV E6 protein was found to bind p53 and inhibit cell apoptosis. HPV E7 proteins binding to retinoblastoma protein $(\mathrm{pRb})$ interferes with cell cycle regulation [36, 37]. We found that miR-944 expression was associated with HPV E6/E7 mRNA. However, the relationship between miR-944 and p53 or pRb, which showed a relationship with HPV E6/E7, in cervical cancer progression was not evaluated. Further studies are needed to evaluate the functional role of miR-944 with p53 or pRb to understand the progression of cervical cancer.

The limitation of this study was the small sample size with single institution. Nevertheless, this study was valuable that miR-944 was shown potential marker complementing conventional clinical prognostic parameters and the relation to HPV E6/E7 positive cervical cancer tissues. It may be worthwhile to conduct replication to clarify our findings with sufficient clinical sample set.

\section{Conclusions}

In conclusion, our results show that miR-944 was highly expressed in cervical cancer tissues and this was associated with FIGO stage, lymph node metastasis, and tumor size. Moreover, elevated expression of miR-944 was correlated with poor survival. Therefore, our data suggest that miR-944 could be used as a prognostic marker in cervical cancer.

\section{Additional files}

Additional file 1: Relative expression of miR-944 in HPV-infected and HPV non-infected cervical cancer cell lines. The relative expression level of miR-944 was evaluated in five types of cervical cancer cell lines: C33A, SiHa, Caski, HeLa, and ME180. miR-944 was significantly up-regulated in SiHa (HPV 16), Caski (HPV 16), HeLa (HPV 18), and ME-180 (HPV 18, 68) cervical cancer cell lines compared to in the C33A (HPV-negative) cervical cancer cell line. (PPTX $74 \mathrm{~kb}$ )

Additional file 2: Clinical information from TCGA data. (PPTX $41 \mathrm{~kb}$ )

Additional file 3: miR-944 expression levels according to HPV E6/E7positive vs. HPV E6/E7-negative cervical cancer in TCGA. The expression levels of miR-944 for 171 HPV E6/E7- positive cervical cancer patients including HPV a9 and HPV a7 species group and 9 HPV E6/E7- negative cervical cancer patients were analyzed. The expression level of miR-944 was significantly higher in the HPV E6/E7-positive cervical cancer patients than in the HPV E6/E7-negative cervical cancer patients $(P<0.0001)$. (PPTX $125 \mathrm{~kb}$ )

\section{Abbreviations}

AUC: Area under the curve; cDNA: Complementary DNA; Cl: Confidence interval; $C_{T}$ : Cycle threshold; DMEM: Dulbecco's modified Eagle's medium; FBS: Fetal bovine serum; FFPE: Formalin-fixed paraffin-embedded; FIGO: International Federation of Gynecology and Obstetrics; HPV: Human papillomavirus; HR-HPV: High-risk human papillomavirus; pRB: Retinoblastoma protein; ROC: Receiver operator characteristic; RT: Reverse transcriptase; RTqPCR: Reverse transcription quantitative PCR; TCGA: The Cancer Genome Atlas; WHO: World Health Organization

\section{Acknowledgments \\ Not applicable}

\section{Funding}

This work was supported by the Basic Science Research Program of the National Research Foundation of Korea (NRF) funded by the Ministry of Science, ICT, and Future Planning (grant no. 2015R1A2A2A04004455). The funding bodies had no role in the study design, data collection, analysis, interpretation of data, and writing of the manuscript.

\section{Availability of data and materials}

All data generated or analysed during this study are included in this published article and its additional files.

\section{Authors' contributions}

DC and HL participated in conceptualization and supervised all the analysis. SP and JK managed miRNA data and TCGA data and analyzed prognostic statistics and wrote an original draft. SO, KE and GK performed sample preparation. KHP were prepared clinical samples and interpreted histological examination. DC interpreted clinical examination and advised interpretation of prognostic statistics. SK, SA, and GK edited the original script and advised data. All authors read and approved the final manuscript. 


\section{Ethics approval and consent to participate}

This study was approved by the Institutional Ethics Committee of Yonsei University Wonju Severance Christian Hospital (approval no. CR315052), and all subjects provided written informed consent.

\section{Consent for publication}

Not applicable

\section{Competing interests}

The authors declare they have no competing interests.

\section{Publisher's Note}

Springer Nature remains neutral with regard to jurisdictional claims in published maps and institutional affiliations.

\section{Author details}

'Department of Biomedical Laboratory Science, College of Health Sciences, Yonsei University, 1 Yonseidae-gil, Wonju-si, Gangwon-do 26493, Republic of Korea. ${ }^{2}$ Department of Clinical Laboratory Science, College of Health Sciences, Catholic University of Pusan, Pusan, South Korea. ${ }^{3}$ Department of Pathology, Yonsei University, Wonju College of Medicine, Wonju, South Korea. ${ }^{4}$ Department of Obstetrics and Gynecology, Gangnam Severance Hospital, Yonsei University College of Medicine, 146-92 Dongok-dong, Gangnam-gu, Seoul, Republic of Korea.

\section{Received: 29 October 2018 Accepted: 16 April 2019}

\section{Published online: 06 May 2019}

\section{References}

1. Torre LA, Bray F, Siegel RL, Ferlay J, Lortet-Tieulent J, Jemal A. Global cancer statistics, 2012. CA Cancer J Clin. 2015;65(2):87-108.

2. McGuire S. World Cancer report 2014. Geneva, Switzerland: World Health Organization, International Agency for Research on Cancer, WHO press, 2015. Adv Nutr. 2016;7(2):418-9.

3. zur Hausen H. Papillomavirus infections--a major cause of human cancers. Biochim Biophys Acta. 1996;1288(2):F55-78.

4. Forouzanfar MH, Foreman KJ, Delossantos AM, Lozano R, Lopez AD, Murray CJ, Naghavi M. Breast and cervical cancer in 187 countries between 1980 and 2010: a systematic analysis. Lancet. 2011;378(9801):1461-84.

5. Bartel DP. MicroRNAs: genomics, biogenesis, mechanism, and function. Cell. 2004;116(2):281-97.

6. Bouyssou JM, Manier S, Huynh D, Issa S, Roccaro AM, Ghobrial IM Regulation of microRNAs in cancer metastasis. Biochim Biophys Acta. 2014;1845(2):255-65.

7. Hebert SS, De Strooper B. Alterations of the microRNA network cause neurodegenerative disease. Trends Neurosci. 2009:32(4):199-206.

8. Esquela-Kerscher A, Slack FJ. Oncomirs - microRNAs with a role in cancer. Nat Rev Cancer. 2006;6(4):259-69.

9. Guo J, Miao Y, Xiao B, Huan R, Jiang Z, Meng D, Wang Y. Differential expression of microRNA species in human gastric cancer versus nontumorous tissues. J Gastroenterol Hepatol. 2009:24(4):652-7.

10. Lui WO, Pourmand N, Patterson BK, Fire A. Patterns of known and novel small RNAs in human cervical cancer. Cancer Res. 2007:67(13):6031-43.

11. Iorio MV, Ferracin M, Liu CG, Veronese A, Spizzo R, Sabbioni S, Magri E, Pedriali M, Fabbri M, Campiglio M, et al. MicroRNA gene expression deregulation in human breast cancer. Cancer Res. 2005;65(16):7065-70.

12. Takamizawa J, Konishi H, Yanagisawa K, Tomida S, Osada H, Endoh $H_{\text {, }}$ Harano T, Yatabe Y, Nagino M, Nimura Y, et al. Reduced expression of the let-7 microRNAs in human lung cancers in association with shortened postoperative survival. Cancer Res. 2004;64(11):3753-6.

13. Michael MZ, SM OC, van Holst Pellekaan NG, Young GP, James RJ. Reduced accumulation of specific microRNAs in colorectal neoplasia. Mol Cancer Res. 2003;1(12):882-91.

14. He Z, Xu H, Meng Y, Kuang Y. miR-944 acts as a prognostic marker and promotes the tumor progression in endometrial cancer. Biomed Pharmacother. 2017:88:902-10.

15. He H, Tian W, Chen H, Jiang K. MiR-944 functions as a novel oncogene and regulates the chemoresistance in breast cancer. Tumour Biol. 2016;37(2): 1599-607.
16. Xie H, Lee L, Scicluna P, Kavak E, Larsson C, Sandberg R, Lui WO. Novel functions and targets of miR-944 in human cervical cancer cells. Int J Cancer. 2015;136(5):E230-41.

17. Powrozek T, Kuznar-Kaminska B, Dziedzic M, Mlak R, Batura-Gabryel H, Sagan D, Krawczyk P, Milanowski J, Malecka-Massalska T. The diagnostic role of plasma circulating precursors of miRNA-944 and miRNA-3662 for non-small cell lung cancer detection. Pathol Res Pract. 2017;213(11):1384-7.

18. Flores-Perez A, Marchat LA, Rodriguez-Cuevas S, Bautista VP, Fuentes-Mera L Romero-Zamora D, Maciel-Dominguez A, de la Cruz OH, Fonseca-Sanchez M, Ruiz-Garcia E, et al. Suppression of cell migration is promoted by miR944 through targeting of SIAH1 and PTP4A1 in breast cancer cells. BMC Cancer. 2016;16:379

19. Pan T, Chen W, Yuan X, Shen J, Oin C, Wang L, miR-944 inhibits metastasis of gastric cancer by preventing the epithelial-mesenchymal transition via MACC1/met/AKT signaling. FEBS Open Bio. 2017;7(7):905-14.

20. Wen L, Li Y, Jiang Z, Zhang Y, Yang B, Han F. miR-944 inhibits cell migration and invasion by targeting MACC1 in colorectal cancer. Oncol Rep. 2017;37(6):3415-22.

21. Yang YC, Shyong WY, Chang MS, Chen YJ, Lin CH, Huang ZD, Wang HMT, Chen ML. Frequent gain of copy number on the long arm of chromosome 3 in human cervical adenocarcinoma. Cancer Genet Cytogenet. 2001;131(1):48-53.

22. Walboomers JMM, Jacobs MV, Manos MM, Bosch FX, Kummer JA, Shah KV, Snijders PJF, Peto J, Meijer CJLM, Munoz N. Human papillomavirus is a necessary cause of invasive cervical cancer worldwide. J Pathol. 1999; 189(1):12-9.

23. zur Hausen H. Papillomaviruses causing cancer: evasion from host-cell control in early events in carcinogenesis. J Natl Cancer Inst. 2000;92(9):690-8.

24. Howie HL, Katzenellenbogen RA, Galloway DA. Papillomavirus E6 proteins. Virology. 2009;384(2):324-34

25. McLaughlin-Drubin ME, Munger K. The human papillomavirus E7 oncoprotein. Virology. 2009;384(2):335-44.

26. Wang XH, Wang HK, Li Y, Hafner M, Banerjee NS, Tang S, Briskin D, Meyers C, Chow LT, Xie $X$, et al. microRNAs are biomarkers of oncogenic human papillomavirus infections. P Natl Acad Sci USA. 2014;111(11):4262-7.

27. Lajer CB, Garnaes E, Friis-Hansen L, Norrild B, Therkildsen MH, Glud M, Rossing M, Lajer H, Svane D, Skotte L, et al. The role of miRNAs in human papillomavirus (HPV)-associated cancers: bridging between HPV-related head and neck cancer and cervical cancer. Br J Cancer. 2012;106(9):1526-34

28. Cancer Genome Atlas Research. N, Albert Einstein College of M, analytical biological S, Barretos Cancer H, Baylor College of M, Beckman Research Institute of City of $\mathrm{H}$, Buck Institute for research on a, Canada's Michael smith genome sciences C, Harvard medical S, Helen FGCC et al: Integrated genomic and molecular characterization of cenvical cancer. Nature. 2017:543(7645):378-84.

29. Banister CE, Liu C, Pirisi L, Creek KE, Buckhaults PJ. Identification and characterization of HPV-independent cervical cancers. Oncotarget. 2017:8(8):13375-86

30. Ma J, Mannoor K, Gao L, Tan A, Guarnera MA, Zhan M, Shetty A, Stass SA, Xing L, Jiang $F$. Characterization of microRNA transcriptome in lung cancer by nextgeneration deep sequencing. Mol Oncol. 2014;8(7):1208-19.

31. Wang C, Jiang T. MicroRNA-335 represents an independent prognostic marker in cenvical cancer. Tumour Biol. 2015;36(8):5825-30.

32. Azizmohammadi S, Safari A, Azizmohammadi S, Kaghazian M, Sadrkhanlo M Yahaghi E, Farshgar R, Seifoleslami M. Molecular identification of miR-145 and miR9 expression level as prognostic biomarkers for early-stage cervical cancer detection. QJM. 2017:110(1):11-5.

33. Jiang W, Pan JJ, Deng YH, Liang MR, Yao LH. Down-regulated serum microRNA101 is associated with aggressive progression and poor prognosis of cervical cancer. J Gynecol Oncol. 2017;28(6):e75.

34. Christensen LL, Tobiasen H, Holm A, Schepeler T, Ostenfeld MS, Thorsen K, Rasmussen MH, Birkenkamp-Demtroeder K, Sieber OM, Gibbs P, et al. MiRNA-362$3 p$ induces cell cycle arrest through targeting of E2F1, USF2 and PTPN1 and is associated with recurrence of colorectal cancer. Int J Cancer. 2013;133(1):67-78.

35. Nordentoft I, Birkenkamp-Demtroder K, Agerbaek M, Theodorescu D, Ostenfeld MS, Hartmann A, Borre M, Orntoft TF, Dyrskjot L. miRNAs associated with chemosensitivity in cell lines and in advanced bladder cancer. BMC Med Genet. 2012;5:40.

36. Thomas M, Pim D, Banks L. The role of the E6-p53 interaction in the molecular pathogenesis of HPV. Oncogene. 1999;18(53):7690-700.

37. Caldeira S, Dong W, Tommasino M. Analysis of E7/Rb associations. Methods Mol Med. 2005;119:363-79. 